\title{
Oocyte maturation, fertilization and embryo development in vitro and in vivo in the gaur (Bos gaurus)
}

\author{
L. A. Johnston ${ }^{1}$, J. J. Parrish ${ }^{2}$, R. Monson ${ }^{2}$, \\ L. Leibfried-Rutledge ${ }^{2}$, J. L. Susko-Parrish'², D. L. Northey², \\ J. J. Rutledge ${ }^{2}$ and L. G. Simmons ${ }^{1}$ \\ ${ }^{1}$ Omaha's Henry Doorly Zoo, 3701 S 10th St Omaha NE 68107, USA; and 'Department of \\ Meat and Animal Science, University of Wisconsin, Madison WI 53706, USA
}

\begin{abstract}
A study was conducted to evaluate the potential of rescuing immature oocytes from the ovaries of an endangered wild bovid, the gaur (Bos gaurus). Recovered, immature gaur oocytes $(n=59)$ placed in culture were evaluated for: (I) nuclear maturation after $22 \mathrm{~h}$ of culture, (2) fertilization with either thawed homologous (gaur) or heterologous (Bos taurus) spermatozoa $18 \mathrm{~h}$ after insemination and (3) embryo development. Gaur oocytes $(n=6)$ evaluated by fixation and staining at $22 \mathrm{~h}$ had all matured to metaphase II in vitro. Insemination of gaur oocytes in vitro resulted in normal fertilization (defined as the presence of spermatozoa head or two pronuclei) and embryo development to the two- and four-cell stage of $53.6 \%$ ( 15 of 28 ) and $50.0 \%$ (9 of 18), respectively, using homologous spermatozoa. The incidence of normal fertilization of in vitro matured (IVM) gaur oocytes with heterologous spermatozoa was $53.8 \%$ (7 of 13). Insemination of domestic cow oocytes in vitro resulted in normal fertilization and embryo development of $41.7 \%$ (45 of 108) and $60.0 \%$ ( 12 of 20 ), respectively, using heterologous spermatozoa. Two of four gaur embryos $(50 \%)$ developed to the blastocyst stage by day 7 . Embryo transfer of these two conspecific gaur blastocysts into two Holstein recipients resulted in one confirmed pregnancy. One live-born calf was delivered by Caesarian section 308 days after embryo transfer. These results demonstrate the potential of combined IVM and IVF for recovering immature germplasm from an endangered species. Specifically, immature gaur ovarian oocytes are capable of in vitro maturation and fertilization with thawed homologous spermatozoa. The resulting embryos are capable of advancing to blastocysts in culture and of producing live-born offspring after embryo transfer.
\end{abstract}

\section{Introduction}

The gaur (Bos gaurus) is the largest species of extant wild cattle (males, $700-1000 \mathrm{~kg}$; females, $550-700 \mathrm{~kg}$ body weight), inhabiting deciduous and tropical rainforests throughout southeastern Asia. Because of illegal hunting, disease spread from domesticated bovids and habitat fragmentation and loss, gaur populations have declined markedly, leaving only remnant populations in Nepal, India, Thailand, Laos, Burma, Cambodia, Vietnam and Malaysia. Eventually, these small populations will become vulnerable to detrimental genetic and demographic effects (Gilpin and Soule, 1986). Captive propagation offers a complementary strategy for enhancing and protecting the genetic diversity of rare, wild populations. However, to fulfil this role, captive populations need to be carefully managed.

Reproductive biotechniques including artificial insemination (AI), in vitro maturation (IVM), in vitro fertilization (IVF), and gamete/embryo cryopreservation/transfer will play an import- ant role in sustaining genetic diversity in the management of both captive and natural populations (Wildt, 1992; Wildt et al., 1992). For most endangered species, a research model does not exist; however, for wild cattle species, domestic cattle provide an excellent model system to adapt assisted reproductive strategies. A number of laboratories have been actively involved in the basic research and commercial development of IVM and IVF for domestic cattle (review, Leibfried-Rutledge et al., 1989). Furthermore, wildlife breeding programmes have long considered the potential of domestic cattle technology for species preservation. For example, the first nondomesticated species produced by embryo transfer was a gaur calf born to a Holstein cow in 1981 (Stover et al., 1981). More recently, artificial insemination (AI) techniques developed for commercial breeds of cattle have been applied successfully to captive gaur (Junior et al., 1990). Two of six gaur cows were synchronized with prostaglandin, artificially inseminated with frozen-thawed spermatozoa and live offspring were produced (Junior et al., 1990). From a captive management perspective, the Species Survival Plan for the North American Gaur, under the 
auspices of the Association of American Zoological Parks and Aquariums, has begun to establish a cryopreservation bank containing spermatozoa of genetically valuable, captive males that is destined for AI or IVF use.

The present study was conducted to determine whether defined IVM and IVF conditions, as developed for domestic cattle (Bos taurus), were adaptable to a wild bovid, the gaur. Domestic bull spermatozoa and oocytes were used as maturation and fertilization controls in cross-hybridization treatments. The specific objectives were to: (1) evaluate the IVM ability of gaur oocytes, (2) assess the ability of gaur IVM oocytes to be fertilized with either frozen-thawed homologous (gaur) or heterologous (domestic bull) spermatozoa and (3) evaluate the ability of the resulting homologous embryos to develop in vitro and in vivo.

\section{Materials and Methods}

\section{Ovary collection and maturation}

Gaur ovaries were collected post-mortem from three adult gaur cows and maintained at ambient temperature for 7-8 $\mathrm{h}$ during transport to the laboratory for processing. Follicular contents from all superficial follicles were aspirated with an 18-gauge needle and placed into a culture dish containing modified Tyrode's medium that contained Hepes (TL-Hepes, Parrish et al., 1986). Oocytes were classified as: (1) immature, excellent-to-good (uniform pigmentation and compact cumulus cells), (2) immature, fair-to-poor (partial to no cumulus investments and uneven pigmentation) and (3) mature (prominent cumulus cell expansion) (Leibfried and First, 1979). Six excellent-to-good oocytes ( 2 oocytes per female) and all fair-to-poor and mature oocytes were fixed and stained immediately to assess nuclear status before culture.

Domestic cattle oocytes were used as maturation and fertilization controls. Ovaries were obtained from an abattoir and transported within $6 \mathrm{~h}$ to the laboratory in saline $\left(35^{\circ} \mathrm{C}\right)$. Follicles ( $\mathrm{I}-5 \mathrm{~mm}$ in diameter) were aspirated using an 18-gauge needle and placed into a culture dish containing TL-Hepes. Oocytes were classified as described above, and excellent-to-good oocytes were placed into culture.

Immature oocytes (gaur, $n=59$; domestic cow, $n=170$ ) were washed four times in TL-Hepes before placing into maturation medium 199 (TCM-199) supplemented with $0.2 \mathrm{mmol}$ pyruvate $1^{-1}, 10 \%$ heat-treated fetal calf serum, gentamicin $\left(25 \mu \mathrm{g} \mathrm{ml}^{-1}\right), 0.5 \mu \mathrm{g}$ ovine FSH ml${ }^{-1}(\mathrm{NIH}$, Bethesda, MD), $5 \mu \mathrm{g}$ ovine $\mathrm{LH} \mathrm{ml}^{-1}(\mathrm{NIH})$ and $1 \mu \mathrm{g}$ oestradiol ml ${ }^{-1}$ (Sigma Chemical Co., St Louis, MO). Oocytes were cultured for $22 \mathrm{~h}$ at $39^{\circ} \mathrm{C}$ under an atmosphere of $5 \% \mathrm{CO}_{2}$ in air and with high humidity. After $22 \mathrm{~h}$ in culture, six gaur oocytes were randomly selected, fixed and stained to assess nuclear status. The remaining gaur oocytes ( $n=53$ ) were divided randomly and processed for one of three IVF treatments (see below). Domestic cow oocytes were processed for insemination with heterologous (gaur) spermatozoa.

Nuclear status, before and after culture, was evaluated by mounting oocytes on slides beneath coverslips supported by a mixture of paraffin and petroleum jelly, cleared in acetic acid: ethanol (1:3) for $24 \mathrm{~h}$ and stained with $1 \%$ orcein in $70 \%$ glacial acetic acid and observed with Nomarski optics under a Zeiss photomicroscope (Leibfried and First, 1979). Oocytes reaching anaphase I, telophase I or metaphase II of meiosis were classified as mature. All oocytes that contained two pronuclei or normally cleaved after IVF were classified retrospectively as mature.

\section{In vitro insemination}

The ability of IVM gaur oocytes to become fertilized was assessed by insemination with: (1) thawed gaur spermatozoa and (2) previously characterized thawed domestic bull spermatozoa. Thawed spermatozoa from three gaur bulls (1 straw per bull) and one domestic bull were used. Because IVF conditions for spermatozoa vary with individual bulls (Iritani et al., 1986; Parrish et al., 1986), thawed semen from the three gaur bulls were pooled. Thawed semen samples were processed on a discontinuous Percoll gradient (Susko-Parrish et al., 1992). Briefly, a Percoll gradient was made with $2 \mathrm{ml} 90 \%$ Percoll on the bottom of a $15 \mathrm{ml}$ conical tube and $2 \mathrm{ml}$ of $45 \%$ Percoll on top. Samples were layered gently on top of the gradient and centrifuged $(700 \mathrm{~g}, 20 \mathrm{~min})$; the top layers were then decanted and the spermatozoa pellet recovered. The concentration of spermatozoa was determined and diluted to one of two insemination concentrations.

IVM gaur oocytes designated for insemination were washed three times in TL-Hepes and 5-10 oocytes transferred to $50 \mu \mathrm{l}$ drops of fertilization medium (Leibfried-Rutledge et al., 1987). The following spermatozoa treatments were added to each drop of fertilization medium: (1) $1 \times 10^{6}$ gaur spermatozoa $\mathrm{ml}^{-1}$ ( $n=13$ oocytes), (2) $5 \times 10^{6}$ gaur spermatozoa $\mathrm{ml}^{-1}$ ( $n=15$ oocytes) or (3) $1 \times 10^{6}$ domestic bull spermatozoa $\mathrm{ml}^{-1}$ ( $n=13$ oocytes). Twelve inseminated gaur oocytes were destroyed during fixation/staining. The IVM domestic cow oocytes were processed in the same way as the gaur oocytes and transferred to one of two fertilization drops containing either $1 \times 10^{6}$ or $5 \times 10^{6}$ gaur spermatozoa $\mathrm{ml}^{-1}$ ( $n=92$ and 78 oocytes, respectively). Spermatozoa and oocytes were co-incubated for $18 \mathrm{~h}$ at $39^{\circ} \mathrm{C}$ under an atmosphere of $5 \% \mathrm{CO}_{2}$ in air and with high humidity.

\section{Fertilization assessment and in vitro development}

Fertilization success was determined by randomly selecting oocytes from each insemination group and processing as described above for nuclear status at $18 \mathrm{~h}$ after insemination. Monospermic fertilized oocytes were classified as having: (I) a sperm head in cytoplasm without pronuclear development, (2) a single pronucleus with sperm head in cytoplasm or (3) two pronuclei with or without sperm tail remnants. Oocytes containing three or more pronuclei with or without sperm tail remnants were considered polyspermic.

The remaining inseminated oocytes designated for development in vitro were washed and placed in CRI medium, supplemented with Minimum Essential Medium and Basal Medium Eagle amino acids under $5 \% \mathrm{CO}_{2}$ in air (Rosenkrans and First, 1991). Inseminated oocytes were cultured for an additional $24 \mathrm{~h}$ to assess cleavage. Embryos were fixed and stained as described above for nuclear status. Normal embryo 


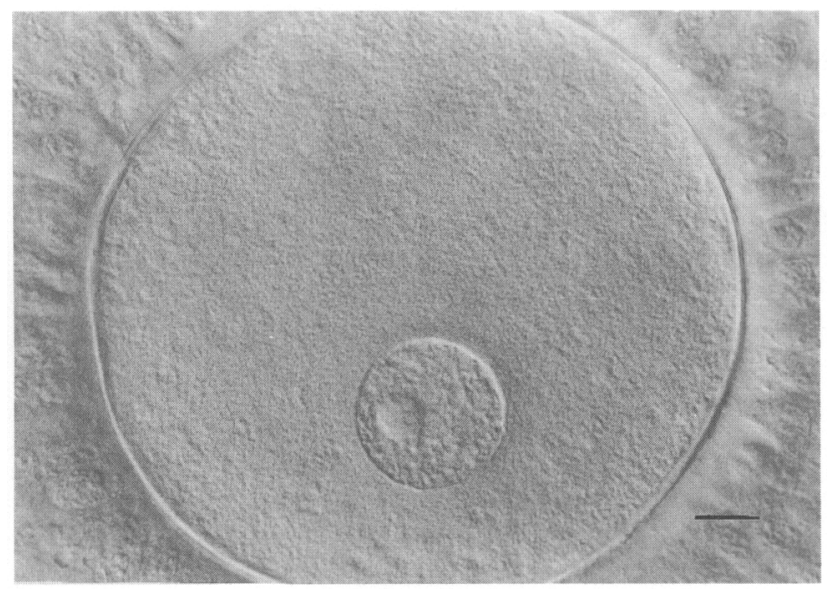

Fig. 1. Freshly isolated immature gaur oocyte at germinal vesicle stage. Bar represents $10 \mu \mathrm{m}$.

development was defined as the presence of one nucleus per blastomere. A proportion of inseminated oocytes (gaur, $n=4$; domestic cow, $n=62$ ) was cultured for 7-8 days to monitor potential growth to the blastocyst stage.

\section{Statistical analysis}

The proportion of oocytes maturing, fertilizing after co-culture with spermatozoa and the proportion of developing embryos at a specific stage are expressed as percentages. Differences in fertilization and embryo development were evaluated by $\chi^{2}$.

\section{Results}

\section{Oocyte recovery}

Overall, 95 oocytes were recovered from the three sets of gaur ovaries. Sixty-five $(68.4 \%)$ of these were classified as excellent-to-good, $11(11.6 \%)$ as poor and $19(20 \%)$ designated mature. Preculture meiotic stage analysis of the six representative excellent quality gaur oocytes revealed that all were at the germinal vesicle stage (Fig. 1). Of the gaur oocytes designated as poor $(n=10)$ or mature $(n=20)$, eight $(80 \%)$ and seven $(35 \%)$ contained germinal vesicles, respectively. Of the remaining two oocytes classified as poor, one contained a degenerative germinal vesicle and the other was degenerate. Oocytes classified as mature also exhibited $40 \%$ degenerative germinal vesicles, $15 \%$ metaphase II, and $10 \%$ were completely degenerate.

\section{Nuclear maturation}

At $22 \mathrm{~h}$ of culture, all gaur oocytes showed evidence of cumulus cell expansion similar to that of domestic cow oocytes. Six gaur oocytes (two oocytes per female) randomly selected at this time were at metaphase II with first polar body extrusion. Of the remaining gaur oocytes, $53.7 \%$ (22 of 41 ) were classified

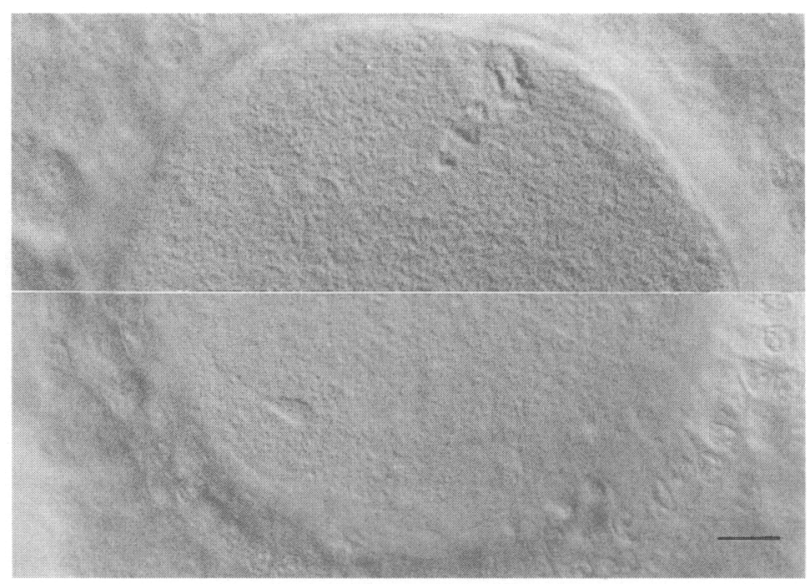

Fig. 2. Normal fertilizaton of domestic cow oocyte with gaur spermatozoa. Spermatozoa and oocyte telephase II configuration are at different focal planes which have been separated by a white line. Bar represents $10 \mu \mathrm{m}$.

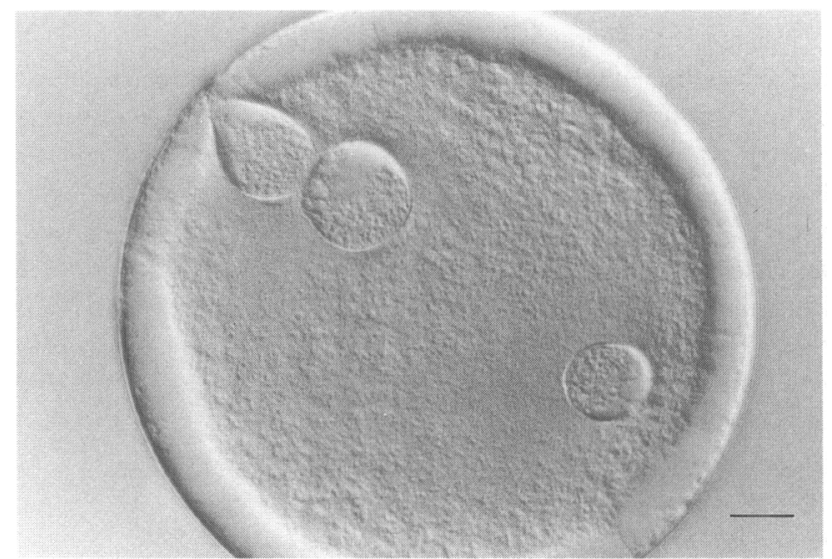

Fig. 3. Polyspermic fertilization of gaur oocyte with gaur spermatozoa. Bar represents $10 \mu \mathrm{m}$

with either normal fertilization or embryo development and considered to have matured to metaphase II.

\section{Fertilization}

Thawed gaur spermatozoa could fertilize IVM gaur oocytes at both insemination doses tested (Table 1). All of the oocytes inseminated at the high concentration of spermatozoa were fertilized and $60 \%$ of the oocytes were fertilized at the lower insemination concentration. Although fertilization was increased at the high insemination dose, a substantial portion was polyspermic $(P<0.05)$ (Table 1$)$. Overall fertilization rates of IVM gaur oocytes inseminated with domestic bull spermatozoa were intermediate $(84.6 \%)$ in comparison with homologous fertilizations. The percentages of monospermic (Fig. 2) and polyspermic (Fig. 3) fertilizations were comparable for heterologous and homologous inseminations at the higher concentration of spermatozoa (Table 1).

Thawed gaur spermatozoa could also fertilize control IVM domestic cow oocytes at both insemination doses tested (Table 
Table 1. Fertilization assessment of gaur and domestic cow oocytes inseminated with gaur or domestic bull spermatozoa

\begin{tabular}{|c|c|c|c|c|c|}
\hline \multicolumn{2}{|c|}{ Species } & \multirow[b]{2}{*}{ Sperm concentration $\left(\times 10^{6}\right)$} & \multirow[b]{2}{*}{ Number of oocytes } & \multicolumn{2}{|c|}{ Fertilization $^{\mathrm{a}}$} \\
\hline Sperm & Oocyte & & & Monospermic $(\%)$ & Polyspermic (\%) \\
\hline Gaur & Gaur & $I$ & 5 & $3(60)^{\mathrm{b}}$ & $0(0)^{b}$ \\
\hline Gaur & Gaur & 5 & 5 & $3(60)^{b}$ & $2(40)^{\mathrm{c}}$ \\
\hline Taurus & Gaur & 1 & 13 & $7(54)^{\mathrm{b}}$ & $4(3 I)^{c}$ \\
\hline Gaur & Taurus & 1 & 51 & $16(31)^{\mathrm{b}}$ & $0(0)^{b}$ \\
\hline Gaur & Taurus & 5 & 37 & $17(46)^{b}$ & $12(32)^{c}$ \\
\hline
\end{tabular}

${ }^{a}$ Criteria for monospermic or polyspermic fertilization are described in Materials and Methods.

b.c Values within columns with different superscripts are significantly different $(P<0.05)$.

Table 2. Development of gaur and hybrid embryos to the two-cell and four-cell stage

\begin{tabular}{|c|c|c|c|c|c|c|}
\hline \multicolumn{2}{|c|}{ Species } & \multirow[b]{2}{*}{ Sperm concentration $\left(\times 10^{6}\right)$} & \multirow[b]{2}{*}{ Number of embryos } & \multirow[b]{2}{*}{2 -cell $(\%)^{a}$} & \multirow[b]{2}{*}{$4-\operatorname{cell}(\%)^{\mathrm{a}}$} & \multirow[b]{2}{*}{ Fragmented 1-cell $(\%)^{\mathrm{ab}}$} \\
\hline Sperm & Oocyte & & & & & \\
\hline Gaur & Gaur & 1 & 7 & $3(43)$ & $0 \quad(0)$ & $4(57)$ \\
\hline Gaur & Gaur & 5 & 7 & $\begin{array}{l}0 \quad(0) \\
2(29)^{c}\end{array}$ & $\begin{array}{l}2(29) \\
2(29)^{\mathrm{c}}\end{array}$ & $1(14)$ \\
\hline Gaur & Taurus & 1 & 10 & $\begin{array}{l}4(40) \\
3(30)^{\mathrm{c}}\end{array}$ & $\begin{array}{l}0(0) \\
1(10)^{\mathrm{C}}\end{array}$ & $2(20)$ \\
\hline Gaur & Taurus & 5 & 10 & $\begin{array}{l}5(50) \\
1(10)^{c}\end{array}$ & $3(30)$ & $1(10)$ \\
\hline
\end{tabular}

${ }^{a}$ Values within columns are not significantly different $(P>0.05)$.

${ }^{b}$ All fragmented one-cell embryos were fertilized.

cAbnormal embryo development.

1). Fertilization rates of domestic cow oocytes obtained with both sperm concentrations were similar $(P>0.05)$ to rates using heterologous or homologous insemination treatment on IVM gaur oocytes (Table 1). The incidence of polyspermy was similar to the incidence in IVM gaur oocytes (Table 1).

\section{Embryo development}

Homologous fertilized gaur oocytes were capable of normal development to the two- and four-cell stage (Table 2). At the lower insemination dose used, all embryos showed normal development. At the higher insemination treatment, there was an increased incidence of abnormal cytokinesis (Table 2). The remaining oocytes in both groups were fertilized and were in the process of fragmentation (Table 2).

On day 7 of culture, two gaur embryos had developed to the morula stage and two were at the early blastocyst stage. The blastocysts were transferred individually into naturally cyclic Holstein recipients at day 7 after oestrus $(n=2)$. The remaining two embryos failed to continue development in vitro. One pregnancy was diagnosed by rectal palpation on day 30. A live-born calf was delivered by Caesarian section 308 days after embryo transfer.

Heterologous fertilization of IVM domestic cow oocytes showed normal embryo development to the two- and four-cell stage for both insemination doses tested (Table 2). The incidence of abnormal development was similar for both sperm treatments (Table 2). Of the remaining 62 hybrid embryos allowed to culture to day 8 , only the embryos from the high sperm concentration group developed into blastocysts ( 9 of 31 , $29.0 \%)$.

\section{Discussion}

This study demonstrated the successful adaptation of IVM, IVF, embryo culture and transfer technology developed for domestic cattle to an endangered wild bovid. Previous studies applying assisted reproduction to endangered species have relied primarily on AI or IVF of in vivo-matured oocytes in an attempt to produce offspring (review, Wildt et al., 1992). The ability to mature and fertilize immature oocytes in vitro would provide one approach for rescuing genetic material from endangered species, including bovids. In captive populations, the most genetically valuable individuals are the founders which are usually quite old. Currently, it is only possible to save genetic material from males through semen cryopreservation. Unfortunately, this only preserves half of the genetic material in the population for future use. Ideally, a programme is needed in which oocytes from valuable females are collected by in vivo aspiration or after post-mortem collection and 
inseminated with thawed spermatozoa from a variety of males. Embryos could be transferred immediately or cryopreserved for future genetic infusion into the population.

Only a few studies have explored the potential of gamete rescue and the application of IVM to endangered species (banteng: Barnes et al., 1988; felids: Johnston et al., 1991; klipspringer: Raphael et al., 1991). The problems these studies have encountered are the rarity of the species and the requirement that most of the raw data must be collected opportunistically from older and medically compromised individuals. As a consequence, these studies have met with only limited success in comparison to studies using domestic or laboratory species (sheep: Moor and Trounson, 1977; cows: Crister et al., 1986; pigs: Mattioli et al., 1989; mice: Schroeder et al., 1991). The extensive data base developed for domestic cows can now be used to begin applying biotechniques to endangered bovids. Although our sample size of gaur oocytes was relatively limited, we were able to draw several important conclusions for future use with this species.

First, it is possible to recover a high percentage of excellent quality ovarian oocytes from gaur ovaries. A high proportion of all gaur oocytes $(68.4 \%)$ recovered were suitable for culture. Although optimal results for maturation occur when cattle oocytes are retrieved from follicles 2-5 $\mathrm{mm}$ in diameter (Leibfried and First, 1979; Fukui and Sakuma, 1980; Suss et al., 1988), follicles of specific-size classes were not aspirated from gaur ovaries in the study reported here. The maturation percentage of gaur oocytes $(59.6 \%)$ is in the middle range of values that have been reported for domestic cattle (for review see Leibfried-Rutledge et al., 1989).

Monospermic IVF rates for homologous and heterologous inseminations of gaur oocytes are similar to values that have been described for domestic bulls (about 30-80\%). However, insemination at the low gaur spermatozoa dose tested revealed about a twofold reduction in fertilization rates of oocytes from domestic cows compared with gaur oocytes. There was not a reduction in fertilization rates when the reciprocal cross using domestic bull spermatozoa was made. Polyspermy occurred at the higher concentration of gaur spermatozoa tested (for both species of oocytes and with domestic bull spermatozoa on gaur oocytes. The incidence of polyspermy in the domestic cattle system has been reported to vary with heparin dose, individual bull and insemination concentration (Parrish et al., 1986; Leibfried-Rutledge et al., 1989; Long et al., 1993). In the study reported here, the frequency of polyspermy was in the upper percentile range reported by other investigators for domestic cattle (range: 10-35\%; Parrish et al., 1986; Long et al., 1993).

Leibfried-Rutledge et al. (1987) reported abnormal cytokinesis and irregular cleavage during early developmental stages of IVM/IVF produced domestic cattle embryos. As this was the first documented study with IVM/IVF using gaur oocytes, it was important to determine the extent of normal development of early cleavage embryos. A portion of gaur and hybrid embryos from all treatment groups showed a similar occurrence of abnormal development resulting in nuclear division without cell division. There did not appear to be a relationship between abnormal development and insemination concentrations.

The first reported pregnancies and live births of domestic calves as a result of IVM/IVF occurred in 1986 (Crister et al., 1986; Hanada et al., 1986). The current success rate of pregnancies using blastocysts produced from the IVM/IVF conditions used in this study are 78\% (14 of 18) (Monson et al., 1992). Despite the extensive efforts to improve embryo development, the yield of morula-blastocyst is still quite low, ranging from 12 to $45 \%$ (Leibfried-Rutledge et al., 1989; Bavister et al., 1992). Although the number of gaur embryos that were cultured was small, all reached the morula-blastocyst stage. Of the hybrid embryos produced, the percentage of blastocysts $(29 \%)$ was within the range reported by other studies. The absence of any hybrid blastocyst development in the lower spermatozoa insemination dose used could reflect the overall reduction in fertilization compared with the high spermatozoa insemination group.

Hybridization between gaur and Bos taurus has been documented in the wild and in captivity (Azman and Hilmi, unpublished data, 1988; Junior et al., 1990). We were able to demonstrate that the success of homologous and heterologous fertilizations were similar, suggesting that fertilization mechanisms between these two species are conserved. Previous reports evaluating in vitro fertilization systems in the domestic bovid have indicated that spermatozoa of individual bulls vary in fertilization frequency, penetration and subsequent embryonic development (Brackett et al., 1982; Sirard and Lambert, 1985; Iritani et al., 1986; Parrish et al., 1986; Leibfried-Rutledge et al., 1987). In addition, individual bull spermatozoa can be defined with precise heparin doses and sperm concentration conditions to give similar standards of fertilization for all bulls (Parrish et al., 1986). The capability to define specific conditions for gaur spermatozoa in vitro using a heterologous system will permit fundamental data to be collected for future application to IVM/IVF work in the gaur.

One of the most important findings of this study was that the IVM/IVF oocytes from this endangered species could be matured in vitro, inseminated with frozen-thawed spermatozoa and used to establish a pregnancy that resulted in a live-born calf. This is the first time this has been reported for an endangered species and demonstrates the utility of this technology in salvaging genetic material from animals. This approach could be immediately used by the organized Gaur Species Survival Plan by requesting ovaries from genetically valuable gaur that die unexpectedly to be shipped immediately to a receiving laboratory for IVM/IVF. Studies are in progress to: (1) define fertilization requirements of genetically valuable bull spermatozoa and (2) evaluate the feasibility of oocyte aspiration on selective gaur cows in vivo and IVF using designated bull semen.

\section{References}

Barnes FL, Balke JME, Eyestone WH, First NL and Read BR (1988) In vitro fertilization of banteng (Bos javanicus): a case report Theriogenology 29216 (Abstract)

Bavister BD, Rose-Hellekant TA and Pinyopummintr T (1992) Development of in vitro matured/in vitro fertilized bovine embryos into morulae and blastocysts in defined culture media Theriogenology 37 127-146

Brackett BG, Bousquet D, Boice ML, Donawick WJ, Evans JF and Dressel MA (1982) Normal development following in vitro fertilization in the cow Biology of Reproduction 27 147-158

Crister ES, Leibfried-Rutledge ML, Eyestone WH, Northey DL and First NL (1986) Acquisition of developmental competence during maturation in vitro Theriogenology 25 (Abstract) 
Fukui $Y$ and Sakuma Y (1990) Maturation of bovine oocytes cultured in vitro: relation to ovarian activity, follicular size and the presence or absence of cumulus cells Biology of Reproduction 22 669-673

Gilpin ME and Soule ME (1986) Minimum viable populations: processes of species extinction. In Conservation Biology: The Science of Scarcity and Diversity pp 19-34 Ed. ME Soule. Sinauer Associates, Sunderland, MA

Hanada A, Shioya $Y$ and Suzuki T (1986) Birth of calves from nonsurgical transfer of blastocysts originated from in vitro fertilized oocytes matured in vitro Japanese Society of Zootechnological Science 118 (Abstract)

Iritani A, Utsumi K, Miyake M and Yamaguchi Y (1986) Individual variation in the in-vitro fertilizing ability of bull spermatozoa Development, Growth and Differentiation 4535 (Abstract)

Johnston LA, Donoghue AM, O'Brien SJ and Wildt DE (1991) Rescue and maturation in vitro of follicular oocytes collected from nondomestic felid species Biology of Reproduction 45 898-906

Junior SM, Armstrong DL, Hopkins SH, Simmons LG, Shiewe MC and Gross TS (1990) Semen cryopreservation and the first successful artificial insemination of gaur (Bos gaurus) Theriogenology 33262 (Abstract)

Leibfried ML and First NL (1979) Characterization of bovine follicular oocytes and their ability to mature in vitro Journal of Animal Science 48 76-86

Leibfried-Rutledge L, Crister ES, Eyestone WH, Northey DL and First NL (1987) Development potential of bovine oocytes matured in vitro or in vivo Biology of Reproduction 36 376-383

Leibfried-Rutledge L, Crister ES, Parrish JJ and First N (1989) In vitro maturation and fertilization of bovine oocytes Theriogenology 31 61-74

Long CR, Chase CN, Balise JJ, Duby RT and Robl JM (1993) Effect of sperm removal time, sperm concentration and motility enhancers of fertilization parameters and development of bovine embryos in vitro Theriogenology 39 261 (Abstract)

Mattioli M, Bacci ML, Galeati G and Seren E (1989) Developmental competence of pig oocytes matured and fertilized in vitro Theriogenology 31 1201-1207

Monson R, Northey DL, Gottfredson R, Peschel DR, Rutledge JJ and Schaefer DM (1992) Pregnancy rates of in vitro produced bovine embryos following nonsurgical transfer Theriogenology 37261 (Abstract)
Moor RM and Trqunson AO (1977) Hormonal and follicular factors affecting maturation of sheep oocytes in vitro and their subsequent developmental capacity Journal of Reproduction and Fertility 49 101-109

Parrish JJ, Susko-Parrish JL, Leibfried-Rutledge ML, Crister ES, Eyestone WH and First NL (1986) Bovine in vitro fertilization with frozen-thawed semen Therigenology 25 591-600

RaphaeI BL, Loskutoff NM, Huntress SL and Kraemer DC (1991) Postmortem recovery, in vitro maturation, and fertilization of klipspringer (Oreotragus oreotragus) Joumal of Zoo and Wildlife Medicine 22 115-118

Rosenkrans CF Jr and First NL (1991) Culture of bovine zygotes to the blastocyst stage: effects of amino acids and vitamins Theriogenology 35266 (Abstract)

Schroeder AC, Johnston D and Eppig JJ (1991) Reversal of postmortem degeneration of mouse oocytes during meiotic maturation in vitro Joumal of Experimental Zoology 258 240-245

Sirard MA and Lambert RD (1985) In vitro fertilization of bovine follicular oocytes obtained by laparoscopy Biology of Reproduction 33 487-494

Stover J, Evans J and Dolensek EP (1981) Inter-species embryo transfer from the gaur to domestic Holstein Proceedings of the American Association of Zoo Veterinarians pp 122-124 Topeka Hills Division Riviana Foods, Tokeka, KA

Susko-Parrish J, Aktas H and Leibfried-Rutledge ML (1992) The effect of energy substrates during maturation on the fertilization and development of bovine oocytes Theriogenology 37305 (Abstract)

Suss U, Wuthrich K and Stranzinger G (1988) Chromosome configurations and time sequence of the first meiotic division in bovine oocytes matured in vitro Biology of Reproduction 38 871-880

Wildt DE (1992) Genetic resource banks for conserving wildlife species: justification, examples and becoming organized on a global basis Animal Reproduction Science 28 247-257

Wildt DE, Monfort SL, Donoghue AM, Johnston LA and Howard JG (1992) Embryogenesis in conservation biology - or how to make an endangered species embryo Theriogenology 37 161-184 